\title{
Correction to: Voxel-wise glioblastoma-survival mapping: new tool, new questions
}

\author{
Philip de Witt Hamer ${ }^{1}$ Emmanuel Mandonnet ${ }^{2,3,4}$
}

Published online: 9 June 2021

(c) Springer-Verlag GmbH Austria, part of Springer Nature 2021

\section{Correction to: Acta Neurochirurgica https://doi.org/10.1007/s00701-021-04843-x}

The correct sentence should be:

Fyllingen et al. have contributed an important next step towards understanding whether the tumor location holds prognostic information for survival [4].

References

1. Brown TJ, Brennan MC, Li M et al (2016) Association of the extent of resection with survival in glioblastoma: a systematic review and meta-analysis. JAMA Oncol 2(11):1460-1469

2. Chaichana KL, Jusue-Torres I, Lemos AM, Gokaslan A, Cabrera-Aldana EE, Ashary A, Olivi A, QuinonesHinojosa A (2014) The butterfly effect on glioblastoma: is volumetric extent of resection more effective than biopsy for these tumors? J Neuro-Oncol 120(3):625-634

3. Ellingson BM, Lai A,Harris RJ et al (2013) Probabilistic radiographic atlas of glioblastoma phenotypes. AJNR Am J Neuroradiol 34(3): 533-540

4. Fyllingen EH, B $\varnothing$ LE, Reinertsen I, Jakola AS, Sagberg LM, Berntsen EM, Salvesen $\varnothing$, Solheim O (2021) Survival of glioblastoma in relation to tumor location: a statistical tumor atlas of a population-based cohort. Acta Neurochir https://doi.org/10.1007/s00701-021-04802-6

5. Müller DMJ, Robe PAJT, Eijgelaar RS et al (2019) Comparing glioblastoma surgery decisions between teams

The original article can be found online at https://doi.org/10.1007/ s00701-021-04843-x.

Emmanuel Mandonnet

mandonnet@mac.com

1 Department of Neurosurgery, VU University Medical Center, Amsterdam, Netherlands

2 Frontlab, Institut du Cerveau (ICM), CNRS UMR 7225, INSERM U1127, Paris, France

3 Hôpital Lariboisière, Paris, France

4 Université de Paris, Paris, France using brainmaps of tumor locations, biopsies, and resections. JCO Clin Cancer Inform 3:1-12

6. Senders JT, Staples P, Mehrtash A, Cote DJ, Taphoorn MJB, Reardon DA, Gormley WB, Smith TR, Broekman ML, Arnaout O (2020) An online calculator for the prediction of survival in glioblastoma patients using classical statistics and machine learning. Neurosurgery 86(2):E184-E192

The original article has been corrected.

Publisher's note Springer Nature remains neutral with regard to jurisdictional claims in published maps and institutional affiliations. 